\title{
ATIVIDADE SÉRICA DE ENZIMAS MUSCULARES em cavalos da raça American Trotter treinados após atividade física
}

\author{
Serum activity of muscle enzymes in trained Standardbred \\ horses after physical activity
}

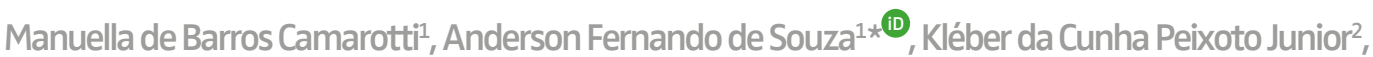 \\ Rafael Sanchez Thomaz ${ }^{3}$, Bruna Carolina Agnello Cruz ${ }^{4}$, Thiago de Azevedo Noronha²
}

\section{*Autor Correspondente: Anderson Fernando de Souza. Av. Prof. Dr. Orlando Marques de Paiva, 87, São Paulo, SP, Brasil. CEP: 05508-270.E-mail: anderson.fs@usp.br}

\begin{abstract}
Como citar: CAMAROTTI, Manuella de Barros; SOUZA, Anderson Fernando de; JUNIOR, Kléber da Cunha Peixoto; THOMAZ, Rafael Sanchez; CRUZ, Bruna Carolina Agnello; NORONHA, Thiago de Azevedo. Atividade sérica de enzimas musculares em cavalos da raça American Trotter treinados após atividade física. Revista de Educação Continuada em Medicina Veterinária e Zootecnia do CRMV-SP, São Paulo, v.18, n. 3, 2020. Doi: $10.36440 /$ recmvz.v18i3.38124

Cite as: CAMAROTTI, Manuella de Barros; SOUZA, Anderson Fernando de; JUNIOR, Kléber da Cunha Peixoto; THOMAZ, Rafael Sanchez; CRUZ, Bruna Carolina Agnello; NORONHA, Thiago de Azevedo. Serum activity of muscle enzymes in trained Standardbred horses after physical activity. Journal of Continuing Education in
\end{abstract}

Animal Science of CRMV-SP, São Paulo, v.18, n.3, 2020. Doi: 10.36440/recmvz.v18i3.38124

\section{Resumo}

Este estudo teve como objetivo avaliar a atividade sérica da creatinoquinase (CK), aspartato aminotransferase (AST), lactato desidrogenase (LDH) e lactato plasmático em cavalos da raça American Trotter após a realização de atividade física. Mensurou-se as concentrações séricas destas enzimas em dois momentos: M1 - imediatamente após o exercício, e M2 - 24 horas após o exercício. Não houveram diferenças entre os momentos para CK, AST e LDH. Para o lactato plasmático, os valores foram maiores em M1. 0 nível de significância foi fixado em $5 \%$. Conclui-se que a atividade física realizada por cavalos American Trotter, em níveis submáximos pouco afeta a atividade sérica de enzimas musculares. 0 bom condicionamento físico favorece a rápida recuperação dos animais após atividades físicas de grande exigência.

Palavras-chave: Bioquímica sérica. Aspartato aminotransferase. Creatinoquinase. Lactatodesidrogenase. Lactato plasmático.

1 Faculdade de Medicina Veterinária e Zootecnia, Universidade de São Paulo (FMVZ-USP), São Paulo, SP, Brasil

2 Universidade Paulista (UNIP), São Paulo, SP, Brasil

3 Médico-veterinário autônomo, São Paulo, SP, Brasil

4 A2 Diagnóstico Veterinário, São Paulo, SP, Brasil 


\section{Abstract}

This study aimed to evaluate the serum activity of creatine kinase (CK), aspartate aminotransferase (AST), lactate dehydrogenase (LDH) and plasma lactate in Standardbred horses after performing physical activity. The serum levels of these enzymes were measured in two moments: M1 immediately after exercise, and M2 24 hours after exercise. There were no differences in CK, AST and LDH concentrations between M1 and M2. For plasma lactate, there were higher values in M1. The level of significance was set at $5 \%$. It concludes that the physical activity performed by Standardbred horses, at submaximal levels, no affects the serum activity of muscle enzymes. Good physical conditioning favors the quick recovery of animals after demanding physical activities.

Keywords: Serum biochemistry. Aspartate aminotransferase. Creatine kinase. Lactate dehydrogenase. Plasma lactate.

\section{Introdução}

Durante a prática de atividades físicas, os diversos sistemas orgânicos dos equinos interagem entre si, em que o entendimento dessa interação e da interdependência é de extrema importância para a avaliação do potencial atlético de cada animal, bem como para o estudo da perda de rendimento dos cavalos, o que auxilia na prescrição de treinos específicos para correção e/ou melhora de limitações individuais (MCGOWAN, 2008; BALARIN et al., 2005).

Devido as intensas exigências competitivas dos equinos atletas, dentre os quais os animais da raça do American Trotter, o estudo da fisiologia do exercício vem cada vez mais se destacando como um recurso imprescindível para o monitoramento da intensidade do treinamento e avaliação de atletas da espécie equina. Esse estudo é fundamental para promover o condicionamento físico respeitando a individualidade do animal, com isso fatores como o overtraining podem ser reduzidos, minimizando lesões na musculatura estriada esquelética (FERRAZ; ESCODRO; QUEIROZ NETO, 2007; HARRIS; MARLIN; SNOW, 1987).

Dentre as principais estratégias para a detecção e acompanhamento clínico de lesões musculares, destaca-se a avaliação da atividade das enzimas creatinoquinase (CK), lactato desidrogenase (LDH) e aspartato aminotransferase (AST) e do lactato plasmático (HURCOMBE, 2020).

Tendo em vista as alterações bioquímicas que ocorrem em consequência do exercício e a sua importância para a avaliação da intensidade do esforço físico, este trabalho foi delineado para avaliar as alterações da atividade sérica de aspartato aminotransferase (AST), creatina kinase (CK), lactato desidrogenase (LDH) e lactato sérico, em equinos da raça American Trotter após a realização de atividade física (Corrida de Trote).

\section{Material e Métodos}

Foram utilizados dez animais da raça American Trotter, três machos e sete fêmeas, entre quatro e 12 anos, oriundos do município de Ribeirão Pires, São Paulo, durante os meses de abril e agosto de 2015. Todos eram alimentados de forma similar, com volumosos e ração de alta qualidade, vacinados e vermifugados rotineiramente, livres de ectoparasitas e hemoparasitoses, Os animais eram submetidos regularmente a exercícios físicos com grau de intensidade semelhante, percorrendo diariamente uma distância de aproximadamente cinco quilômetros ao trote, atrelados ao sulk (Figura 1), adaptado para o treinamento. 


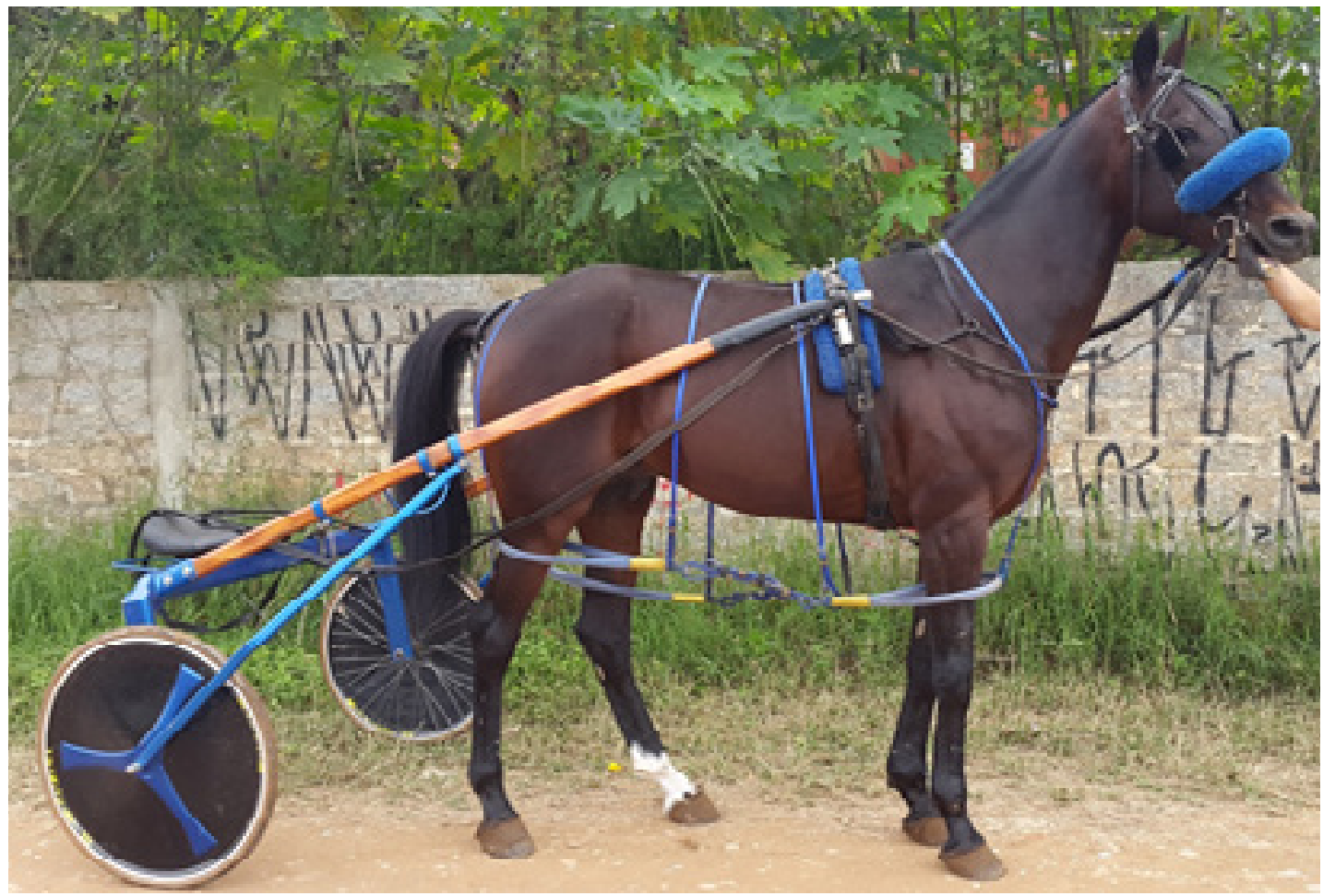

TFonte: Camarotti et al. (2021).

Os animais foram atrelados e realizaram o percurso de cinco quilômetros em pista circular, plana, durante o mesmo período do dia, pelo mesmo condutor. 0 treino foi baseado na simulação da prova, iniciando-se pelo trote em menor velocidade, quefoi aumentando gradativamente até ser atingido o ritmo máximo (velocidade média aproximada de $40 \mathrm{~km} / \mathrm{h}$ ). 0 tempo médio para realização do percurso foi de 10 minutos. Foram colhidas amostras sanguíneas por venopunção jugular externa, com o emprego de um sistema à vácuo em tubos sem anticoagulante, em dois momentos: M1imediatamente após o exercício e M2 - 24 horas após o exercício.

As amostras foram encaminhadas ao laboratório de análises clínicas do Hospital Veterinário da Faculdade de Medicina Veterinária da Universidade Paulista, sob refrigeração, onde foram submetidas a centrifugação por cinco minutos a $3.000 \mathrm{rpm}$ e o soro separado e congelado à -20oC até o momento das análises. A mensuração do lactato foi realizada logo após a colheita, utilizando-se um lactímetro portátil (Accutrend Lactate - Roche ${ }^{\circledR}$ ). No laboratório as amostras sanguíneas foram descongeladas em banho maria e centrifugadas e o soro foi acondicionado em microtubos plásticos tipo Eppendorf de $1,5 \mathrm{ml}$ e em seguida congelados até o momento da realização das análises. Para determinação dos valores de CK, AST e LDH foram utilizados reagentes comerciais específicos para cada enzima, por método colorimétrico em analisador bioquímico (Bio 200, Bioplus ${ }^{\circledR}$ ), seguindo as especificações dos fabricantes.

As médias obtidas nos dois momentos foram comparadas com o emprego do teste $T$, com nível de significância de 5\% (PETRIE; WATSON, 2013). 


\section{Resultados e Discussão}

A atividade física de uma seção de treinamento não provocou efeito mensurável sobre a concentração sérica de enzimas musculares em equinos American Trotter. No presente estudo foi observada uma diminuição significante no valor sérico de lactato entre as colheitas (Tabela 1). Todavia, ambos os valores encontravam-se dentro dos valores de referência para a espécie (KANEKO; HARVEY; BRUSS, 1997), mostrando a ausência de metabolismo anaeróbio detectável. Provavelmente este fato ocorreu devido ao grau de condicionamento e/ou atividade em intensidade compatível com a capacidade metabólica dos animais (GOMES et al., 2020; VERMEULEN et al., 2017).

Nogueira et al. (2002), trabalhando com cavalos de corrida jovens em treinamento com diferentes idades (um a quatro anos), observaram diminuição nos níveis de lactato nos animais mais velhos (três a quatro anos), justamente os apresentavam maior massa muscular, devido ao maior tempo dedicado ao condicionamento físico. Já Rainger et al. (1994), em cavalos Puro Sangue Inglês (PSI) exercitando-se em esteira ergométrica, observaram que os animais treinados apresentaram significantes reduções na concentração de lactato durante o exercício em relação aos animais não treinados.

Harris e Snow (1992), trabalhando com cavalos PSI em esteira, notaram que o pico do lactato ocorreu ao final do exercício para todas as velocidades e que os valores basais foram atingidos após 60 minutos do término do exercício. Marlin e Nankervis (2002) destacaram que se o músculo não produzisse ácido láctico, o exercício só seria limitado às baixas e moderadas intensidades, uma vez que o lactato é essencial para aceleração, velocidade e a realização de esforços intensos.

No presente trabalho não foram observadas diferenças nas concentrações séricas de CK entre os momentos avaliados, contudo os valores registrados foram ligeiramente superiores aos considerados como de referência para a espécie (KANEKO, HARVEY; BRUSS, 1997) (Tabela 1), o que demostra a existência de reposta muscular ao exercício, mas compatível com a intensidade aplicada. 0 aumento da atividade sérica da CK, pode ocorrer sem que isso caracterize injúria muscular, pois após o exercício o aumento da permeabilidade muscular para CK é proporcional a massa muscular do animal (HURCOMBE, 2020).

Toledo et al. (2001), ao trabalharem com cavalos PSI submetidos a exercícios em diferentes intensidades, observaram aumento da CK após exercícios moderado e intenso. Resultados semelhantes foram obtidos por Aitken et al. (1974) com cavalos PSI e Hunter em diferentes intensidades de exercícios, que constataram maiores valores de CK nas atividades mais intensas. A injúrias musculares são caracterizadas pela presença de valores elevados de CK, entre 1.500 e 5.000 U/L (MCEWEN; HULLAND, 1986).

Freestone et al. (1989) relataram que durante o regime de condicionamento, nenhum cavalo apresentou alterações graves da atividade de CK, logo, o metabolismo muscular estava normal e nenhum animal era predisposto a rabdomiólise. 0 mesmo autor, e ainda Valberg (2018) afirmaram que nos animais que atingem elevado grau de condicionamento físico, as concentrações séricas de CK diminuem após o exercício.

No presente trabalho, não foram encontradas diferenças para as concentrações séricas da AST entre os momentos (Tabela 1). Resultados semelhantes foram relatados por Rose, Purdue e Hensley (1977), Freestone et al. (1989) e McEwen e Hulland (1986). Freestone et al. (1989) que concordam em afirmar que os aumentos séricos significantes de AST estão mais relacionados com doença hepática. Já Harris, Marlin e Gray (1998) encontraram aumentos séricos significativos de AST, porém, em cavalos sem nenhum preparo físico. No entanto, Valberg et al. (1993) detectaram variações de AST em decorrência do exercício, acompanhando as variações de CK. 
Ta bela 1. Médias e desvios padrão da atividade sérica das enzimas creatinoquinase (CK), aspartato aminotransferase (AST), lactato desidrogenase (LDH) e lactato plasmático de dez equinos da raça American Trotter, treinados, após a realização de atividade física (Corrida de Trote)

\begin{tabular}{c|c|c}
\hline Variáveis & $\begin{array}{c}\text { Imediatamente após o } \\
\text { exercício }\end{array}$ & $\mathbf{2 4}$ horas após o exercício \\
\hline Lactato (mmol/L) & $3,26 \pm 1,7 a$ & $1,26 \pm 0,53 \mathrm{~b}$ \\
\hline CK (U/L) & $193,38 \pm 30,28 \mathrm{a}$ & $199,37 \pm 58,88 \mathrm{a}$ \\
\hline AST (U/L) & $234,55 \pm 33,94 a$ & $214,71 \pm 20,53 a$ \\
\hline LDH (U/L) & $523,66 \pm 99,94 a$ & $528,03 \pm 60,30 a$ \\
\hline
\end{tabular}

Letras minúsculas distintas na mesma linha indicam diferença estatística $(p<0,05)$.

T Camarotti et al. (2021).

As médias encontradas para os valores de LDH não apresentaram diferenças entre os momentos considerados (Tabela 1). Toledo et al. (2001) também não identificaram alterações desta enzima, antes e após a atividade física em cavalos PSI. Esta enzima não é específica para lesão muscular, sendo também encontrada no fígado e em hemácias (MCKENZIE, 2014). Assim, a interpretação das atividades da LDH, assim como para AST e CK, deve levar em consideração outros indicadores bioquímicos do fígado, como sorbitol desidrogenase, glutamato desidrogenase, gamaglutamiltransferase e concentração total de bilirrubina (HURCOMBE, 2020). Outra opção é a diferenciação de suas isoenzimas, LDH1 (hemólise), LDH2 (cardíaca), LDH4 (intestinal) e LDH5 (esquelética ou hepática) (STOCKHAM; SCOTT, 2008).

\section{Conclusão}

A atividade física, em níveis submáximos, realizada por cavalos American Trotter treinados pouco afetou a concentração sérica de enzimas musculares. 0 bom condicionamento físico favorece a rápida recuperação dos animais após atividades físicas de grande exigência.

\section{Referências}

AITKEN, M. M. et al. Correlations between physiological and biochemical parameters used to assess fitness in the horse. Journal of the South Veterinary African Association, v. 45, n. 4, p. 361-370, 1974.

BALARIN, M. R. S. et al. Avaliação da glicemia e da atividade sérica de aspartato aminotransferase, creatinoquinase, gama-glutamiltransferase e lactato desidrogenase em equinos puro sangue inglês (PSI) submetidos a exercícios de diferentes intensidades. Semina: Ciências Agrárias, v. 26, n. 2, p. 211-218, 2005.

FERRAZ, G. C.; ESCODRO, P. B.; QUEIROZ NETO, A. Fisiologia do exercício equino: Ferramenta para o desempenho atlético de cavalos atletas. Revista Brasileira de Medicina Equina, n. 12, p. 6-8, 2007.

FREESTONE, J. F. et al. Exercise induced changes in creatine kinase and aspartate aminotransferase activities in the horse: Effects of conditioning, exercise tests and acepromazine. Journal of Equine 
Veterinary Science, v. 9, n. 5, p. 275-280, 1989. Disponível em: https://doi.org/10.1016/S07370806(89)80090-5. Acesso em: 22 de jan. 2021.

GOMES, C. L. N. et al. Exercise training session-induced metabolic acidosis in barrel racing horses. Ciência Rural, v. 50, n. 5, e20180887, 2020. Disponível em: https://doi.org/10.1590/01038478cr20180887. Acesso em: 22 de jan. 2021.

HARRIS, R. C.; MARLIN, D. J.; SNOW, D. H. Metabolic response to maximal exercise of 800 and 2,000 $\mathrm{m}$ in the thoroughbred horse. Journal of Applied Physiology, v. 63, p. 12-19, 1987. Disponível em: https://doi.org/10.1152/jappl.1987.63.1.12. Acesso em: 22 de jan. 2021.

HARRIS, P.; SNOW, D. H. Plasma potassium and lactate concentrations in thoroughbred horses during exercise of varying intensity. Equine Veterinary Journal, v. 23, n. 3, p. 220-225, 1992. Disponível em: https://doi.org/10.1111/j.2042-3306.1992.tb02819.x. Acesso em: 22 de jan. 2021.

HARRIS, P. A.; MARLIN, D. J.; GRAY, J. Plasma aspartate aminotransferase and creatine kinase activities in thoroughbred racehorses in relation to age, sex, exercise and training. The Veterinary Journal, $\mathrm{V}$. 155, n. 3, p. 295-304, 1998. Disponível em: https://doi.org/10.1016/S1090-0233(05)80026-7. Acesso em: 22 de jan. 2021.

HURCOMBE, S. D. A. Clinical pathology of the racehorse. Veterinary Clinics of North America: Equine Practice, v. 36, n. 1, p. 135-145, 2020. Disponível em: https://doi.org/10.1016/j.cveq.2019.12.004. Acesso em: 22 de jan. 2021.

KANEKO, J. J.; HARVEY, J. W.; BRUSS, M. L. Clinical biochemistry of domestic animals. San Diego: Academic Press, p. 932, 1997.

MARLIN, D.; K. Equine Exercise physiology. Blackwell Science: Oxford, p. 296, 2002. Disponível em: https://doi.org/10.1016/j.tvjl.2005.03.011. Acesso em: 22 de jan. 2021;

MCEWEN, S. A.; HULLAND, T. J. Histochemical and morphometric evaluation of skeletal muscle from horses with exertional rhabdomyolysis (tying-up). Veterinary Pathology, v. 23, n. 4, p. 400-410, 1986. Disponível em: https://doi.org/10.1177/030098588602300409. Acesso em: 22 de jan. 2021.

MCGOWAN, C. Clinical pathology in the racing horse: the role of clinical pathology in assessing fitness and performance in the racehorse. Veterinary Clinics of North America: Equine Practice, v. 24, n. 2 , p. 405-421, 2008. Disponível em: https://doi.org/10.1016/j.cveq.2008.03.001. Acesso em: 22 de jan. 2021.

MCKENZIE, E. C. Hematology and serum biochemistry of the equine athlete. In: K. HINCHCLIFF, K. W.; KANEPS, A. J.; GEOR, R, J. Equine sports medicine and surgery, 2. ed. Saint Louis: Saunders, p. 921929, 2014. Disponível em: https://doi.org/10.1016/B978-0-7020-4771-8.00042-9. Acesso em: 22 de jan. 2021.

NOGUEIRA, G. P. et al. Serum cortisol, lactate and creatinine concentrations in Thoroughbred fillies of different ages and states of training. Brazilian Journal of Veterinary Research and Animal Science, v. 39, n. 1, p. 54-57, 2002. Disponivel em: https://doi.org/10.1590/S1413-95962002000100010. Acesso em: 22 de jan. 2021.

PETRIE, A.; WATSON, P. Statistics for veterinary and animal science. 3. ed. Ames, lowa: John Wiley \& Sons, 391p. 2013.

RAINGER, J. E. et al. Blood lactate disappearance after maximal exercise in trained and detrained horses. Research in Veterinary Science, v. 57, p. 325-331, 1994. Disponível em: https://doi. org/10.1016/0034-5288(94)90125-2. Acesso em: 22 de jan. 2021.

ROSE, R. J.; PURDUE, R. A.; HENSLEY, W. Plasma biochemistry alterations in horse during an 
endurance ride. Equine Veterinary Journal, v. 9, p. 122-126, 1977. Disponível em: https://doi. org/10.1111/j.2042-3306.1977.tb04002.x. Acesso em: 22 de jan. 2021.

STOCKHAM, S. L.; SCOTT, M. A. Fundamentals of veterinary clinical pathology. 2. ed. Ames, lowa: John Wiley \& Sons, p.928, 2008.

TOLEDO, P. S. et al. Atividade sérica de aspartato aminotransferase, creatina quinase, gamaglutamiltransferase, lactato desidrogenase e glicemia de cavalos da raça P.S.I. submetidos a exercícios de diferentes intensidades. Revista Brasileira de Ciências Veterinárias, v. 8, n. 2, p. 73-77, 2001. Disponível em: http://dx.doi.org/10.4322/rbcv.2015.217. Acesso em: 22 de jan. 2021.

VALBERG, S. J. et al. Muscle histopathology and plasma aspartate aminotransferase, creatine kinase and myoglobinchanges with exercise in horses with recurrentexertional rhabdomyolysis. Equine Veterinary Journal, v. 25, n. 1, p. 11-16, 1993. Disponível em: https://doi.org/10.1111/j.2042-3306.1993. tb02893.x. Acesso em: 22 de jan. 2021.

VALBERG, S. J. Disorders of the Musculoskeletal System. In: REED, S. M.; BAYLY, W. M.; SELLON, D. C. Equine Internal Medicine. 4th ed. Saint Louis: Elsevier, p. 542-579, 2018.

VERMEULEN R. et al. Effects of training on equine muscle physiology and muscle adaptations in response to different training approaches. Vlaams Diergeneeskundig Tijdschrift, v. 86, n. 4, p. 224 230, 2017. Disponível em: https://doi.org/10.21825/vdt.v86i4.16183. Acesso em: 22 de jan. 2021. 